\title{
Corrigendum
}

\section{Corrigendum to "Analytical Method for Evaluating the Ground Surface Settlement Caused by Tail Void Grouting Pressure in Shield Tunnel Construction"}

\author{
Changsheng $W u(\mathbb{D})^{1,2}$ and Zhiduo Zhu $\mathbb{D}^{1,2}$ \\ ${ }^{1}$ Institute of Geotechnical Engineering, Southeast University, Nanjing 210096, China \\ ${ }^{2}$ Jiangsu Key Laboratory of Urban Underground Engineering \& Environmental Safety, Southeast University, \\ Nanjing 210096, China
}

Correspondence should be addressed to Zhiduo Zhu; zhuzhiduo@seu.edu.cn

Received 19 December 2018; Accepted 20 December 2018; Published 3 March 2019

Copyright (c) 2019 Changsheng Wu and Zhiduo Zhu. This is an open access article distributed under the Creative Commons Attribution License, which permits unrestricted use, distribution, and reproduction in any medium, provided the original work is properly cited.

In the article titled "Analytical Method for Evaluating the Ground Surface Settlement Caused by Tail Void Grouting Pressure in Shield Tunnel Construction" [1], Dr. Changsheng $\mathrm{Wu}$ was incorrectly listed as the corresponding author. The corresponding author is Dr. Zhiduo Zhu.

\section{References}

[1] C. Wu and Z. Zhu, "Analytical method for evaluating the Ground Surface settlement caused by Tail void grouting pressure in Shield Tunnel construction," Advances in Civil Engineering, vol. 2018, Article ID 3729143, 10 pages, 2018. 


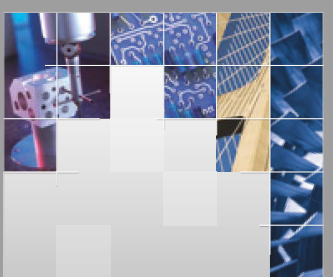

\section{Enfincering}
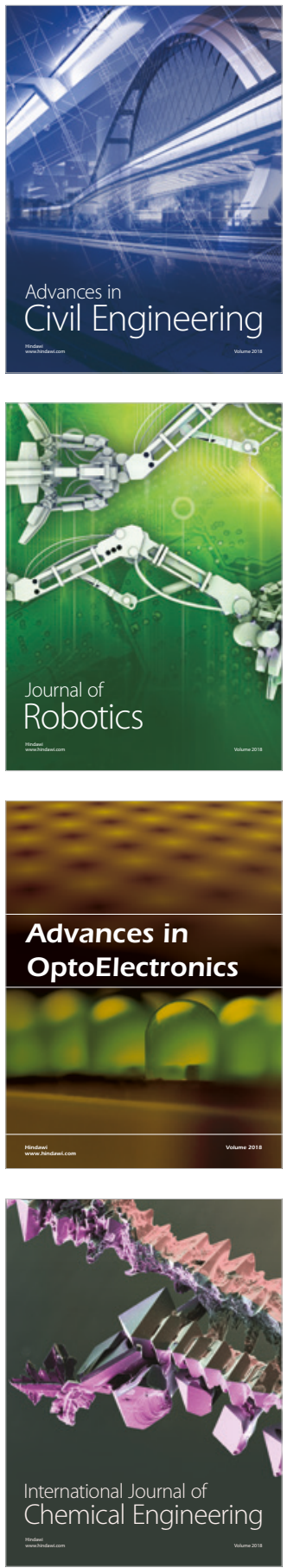

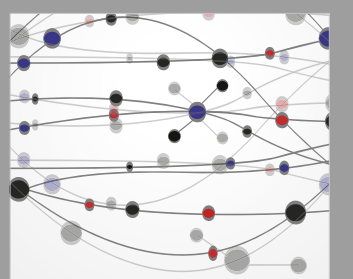

\section{Rotating \\ Machinery}

The Scientific World Journal

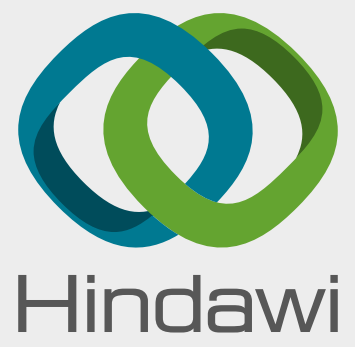

Submit your manuscripts at

www.hindawi.com
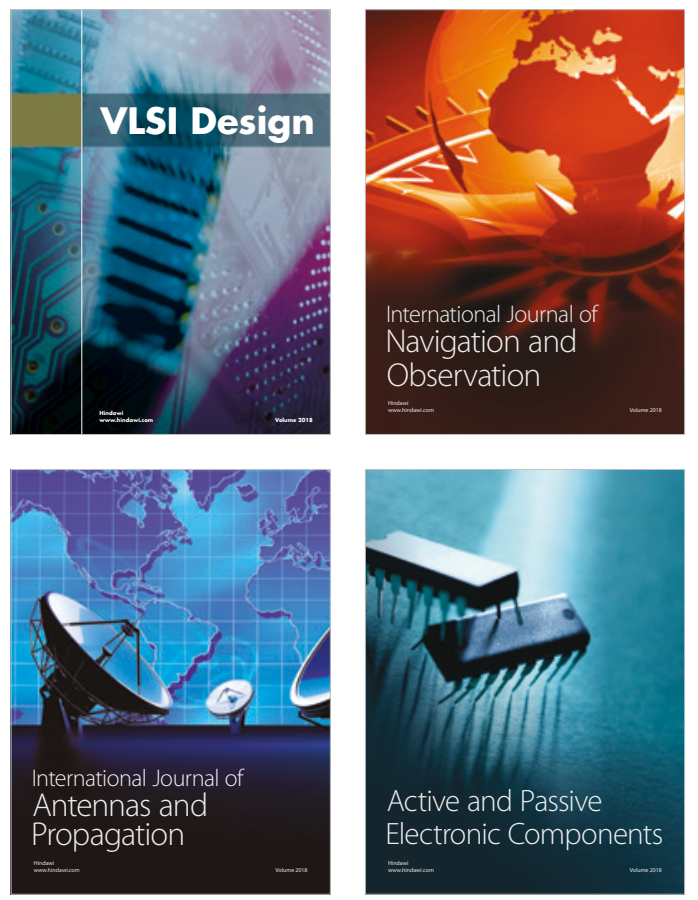
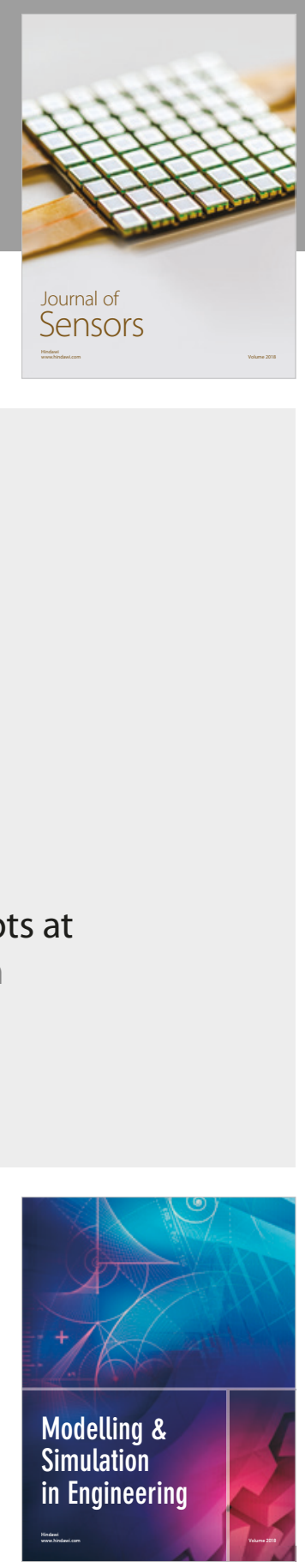

\section{Advances \\ Multimedia}
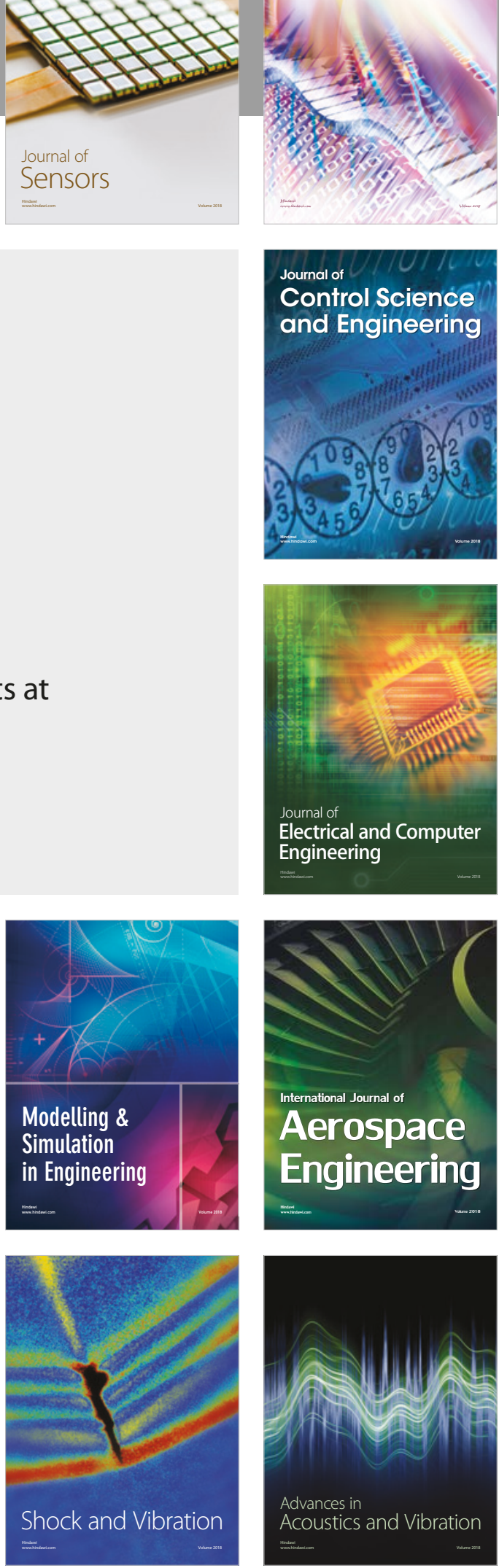